\title{
Virtual Placements Management Process Supported by Technology: Proposal and First Results of the Semester of Code
}

\author{
Francisco J. García-Peñalvo ${ }^{1}$, Juan Cruz-Benito ${ }^{1}$, David Griffiths ${ }^{2}$, Achilleas Achilleos ${ }^{3}$ \\ ${ }^{1}$ Computer Science Department, Research Institute for Educational Sciences (IUCE), GRIAL Research Group, University of Salamanca. Paseo de Canalejas \\ 169,37008, Salamanca, Spain (email fgarcia@usal.es, juancb@usal.es). \\ ${ }^{2}$ University of Bolton, Bolton, UK (e-mail: d.e.griffiths@bolton.ac.uk). \\ ${ }^{3}$ Computer Science Department University of Cyprus, Nicosia, Cyprus, Aglantzia, Chipre (e-mail: achilleas@cs.ucy.ac.cy).
}

\begin{abstract}
This paper explains the Virtual Alliances for Learning Society (VALS) European Project technological approach to support a virtual placements management process. Also, this paper shows the first results of the practical part of the project, the Semester of Code, explaining the detected problems, the issues, the challenges and some actions to improve the development of this kind of virtual placements programmes. In order to allow the readers to better comprehend the approach and its results, the manuscript also describes three of the main virtual placements programs around the world, regarding both their organization and technological approach.
\end{abstract}

Index Terms-Semester of Code, Technological support for placements management, VALS project, Virtual Placements.

\section{INTRODUCTION}

$\mathrm{P}$ programmes that promote the achievement of Higher Education virtual placements at an international level are increasing. The possibility of reducing the physical distance, economic motivations or a greater ratio for finding a job in a global context are significant stimuli for students, enterprises, educational institutions (mainly universities) and managers. They see this kind of processes as an interesting opportunity to achieve internships or facilitate experiences with the real qualified professional environments that provide a significant return for students - in terms of curriculum, future employment opportunities, and professional development- or, in the case of institutions, the perfect opportunity to increase the chances of achieving their objectives of employability and job placement $[1,2]$, also allowing them to increase their international presence at different levels (formative, employability, institutional, etc.) [3-6]. This trend in virtual placements management in international corporations is more common in the Computer Science context and in the disciplines or specialties related to it.

The sharing of knowledge and resources is a fundamental part of the culture in Informatics, Software Engineering or Programming; this can be observed in several areas like the current status of the Open Software and Hardware movements, or the use of social networks and online platforms like public software repositories (Github, Bitbucket, etc.), forums to ask technical questions (like StackOverflow, Quora, ete.) or others that serve both to help other engineers in their work as well as showcases of personal branding for engineers. This culture developed by engineers in these open formulas creates a perfect breeding ground for the adoption of this kind of platforms and its use in the management of virtual (and decentralized) practices in an easier way or even more successful in this type of professional profiles that are accustomed to using systems and tools to work in a nonphysical way (with no physical attendance to a specific workplace).

In order to manage this kind of virtual placements, due to the current development of communications and technological systems, open web platforms are usually employed that make easy the access to the information and the workflow that supports the placement programme running. With regard to these management systems, there is not a common adopted reference; there is no system that stands above the rest or is adopted by the different kinds of placements that are developed internationally. In fact, each placement programme uses its own software system (ad hoc developed or based on a third party's software that initially was not thought to be used to perform these management tasks).

Within this context the European Project Virtual Alliances for Learning Society - VALS (40054-LLP-L-2013-1-ES-ERASMUSEKA) [7] arises, which promotes the establishment of Knowledge Alliances among Higher Education Institutions and the Business world through corporations, foundations and projects, to carry out open innovation processes creating collaboration bridges between the Academia and Business, which allows obtaining feedback from the best of both in pursuit of a common goal of development and innovation based on open philosophies (Open Source [8], Open Innovation [9], Open Knowledge [10-12]). The collaboration proposed by this project is implemented through the development of practices in companies and projects 
worldwide that pose real business problems [13] by students that study computer sciences and other related areas in European educational institutions, in a process regulated by establishing a system of rewards and non-economic compensations which benefits all stakeholders (a win-win approach) [14].

The programme that materializes this collaboration and student placements in companies is called Semester of Code [15] and it is one of the most outstanding tangible results of the project VALS.

The practices system called Semester of Code is composed of several key issues, among which can be highlighted the following:

- A predefined time period for practices, flexible enough to cover the variety of European study plans.

- A process expressly designed to achieve this Semester of Code that serves as scaffolding for the processes of defining projects and tasks, communication among the various possible stakeholders, task management, and the implementation of practices in a common and flexible way for any virtual and professional placement performed by the students involved. This process is called Open Innovation Process and includes the entire life cycle of the practices, from their definition and specification to completion and recognition of the work done.

- A software system that adapts the process known as Open Innovation Process and coordinates the practices workflow for all possible stakeholders involved. It supports, from the point of view of technology, the entire process implemented under the framework of the Semester of Code and acts as a marketplace and meeting point for companies, foundations, projects to be solved, students and academic institutions involved in the experience.

These and other points are developed further in the following sections, but serve as a brief introduction to the intrinsic difficulties, from the point of view of management and organization, of an internship programme as ambitious as the Semester of Code.

This article aims to enlighten the reader about the current state of the systems that manage practices in the field of Informatics and Computer Science. To tackle that, it shows cases of existing programs that offer virtual placements for students in business or industrial environments, presenting examples of how these programs are managed purely in a virtual way or following a mixed approach (the placement and practices take place in a virtual and physical way). Finally, the paper presents the approach and solutions proposed within the VALS European project and its initiative, the Semester of Code.

To accomplish this purpose, the paper is organized in different sections: the first is this brief introduction to programs that manage practices and their difficulties. A section follows (Highlighted Programs of Practices Managed Virtually) that reveals different practical examples of programs that follow virtual philosophies (at least partially) and are success stories in such environments of students involved in professional contexts. In the third section (Semester of Code: Fundamentals and Technological Solution), the reader can find a deeper approach to the Semester of Code's foundations and its technological proposal to support the process of practices. In the fourth section (Results of the Semester of Code's First Iteration) the authors present the results of the first cycle of validation and pilot tests of the Semester of Code and the strengths and weaknesses detected. They also present a brief summary of recommendations and future work regarding the technology system and its workflow. To conclude this article, the authors present the conclusions of this work, compiling the results of both the work and the research associated with the implementation of this initiative related to virtual practices in the European context.

\section{Renowned Programs of Practices Managed Virtually}

In this section three outstanding initiatives are presented that promote knowledge partnerships between academia and business, that coordinate the partnerships through training students of these academic institutions in solving real problems proposed by the industry partner or related to the business world. Among the various projects that handle similar processes, the Summer of Code, the Open Source Undergraduate Capstone Projects, and DEMOLA are among the most suitable to be presented here. The main features of each programme are listed below, so that readers can better understand how some initiatives similar to the VALS project and the Semester of Code are managed, and thus evaluate its proposal and developed system from a better perspective.

\section{A. Summer of Code}

Google's Summer of Code [16] is an initiative that offers students (over 18 years of age) the opportunity to program and perform tasks of code developing for companies and real projects based on Open Source in a totally remote and virtual way, besides getting a payment (USD 5500 in the last edition) for the work done. Moreover, the Summer of Code offers companies, foundations and Open Source projects the possibility of receiving students from anywhere in the world interested in solving any problems they pose (Google also evaluates the proposals for accepting or rejecting their participation in this program).

The Summer of Code started in 2005, and during this time has managed to provide practices to more than 7,500 students from 101 different countries, with over 8000 mentors from 109 countries, and resulting near 50 million lines of developed code [16]. It is therefore a programme really rooted in the international arena, and a referent in the areas of virtual practice among students and companies.

Below is presented a brief description of the functioning of the initiative (based on workflow and conditions of the call at the time of writing this article description, 2015) [17]:

- The companies, foundations and Open Source projects interested in participating in the programme apply one or more projects or project tasks in the Summer of Code website for possible approval and acceptance by Google as part of the 
call for students of the Summer of Code. This proposal should also designate the persons who will act as mentors for students who wish to participate, as well as other details concerning the specific requirements, technologies to be used, etc.

- The company, Google, depending on the theme, the quality of the proposal, the interest, the project path or the mentors' previous experience (among other things) selects or rejects the project to be included in the program.

- After the establishment of the list of projects available to be solved by students, they are posted on the website of the Summer of Code (in the case of the 2015 call http://www.google-melange.com/gsoc/homepage/google/gsoc2015). From this moment, and for two weeks, students can apply for solving any project, proposing to turn in a possible solution as well as other noteworthy details regarding implementation, planning, etc.

- Finally, businesses, foundations and projects choose the best proposals presented by students and the selected students are allotted around three and a half months during the summer to solve the project (usually between May and August).

This description, though possibly extensive for this kind of paper is essential, since the VALS project and Semester of Code take in much of the philosophy that this Summer of Code distills, adopting and adapting its operating philosophy and paradigms to the specific context where VALS and the Semester of Code are applied.

Regarding the technology that supports this workflow and its associated methodology for remote and virtual work, Google has opted for building an ad hoc system known as Melange [18]. In the beginning, Melange coordinated only the workflow of Google's Summer of Code, but now in addition to the management of the workflow it contains a tracker, a content manager and a manager for the communications among the different roles involved, plus other minor applications combined with a framework (called Spice of Creation) that supports them. Melange is developed in Python and is currently based on the backend of Google App Engine. The development of this platform involves a wide range of developers, both of the Google Company itself and members of the Open Source international communities. They develop and improve this system to achieve the adequate support for projects like the Summer of Code or others with similar goals.

\section{B. Undergraduate Capstone Open Source Projects}

The Undergraduate Capstone Open Source Projects (UCOSP) [19] is another programme related to practices and development of projects by students from Canada. The philosophy behind this initiative is somewhat different to those discussed above, because in UCOSP students conduct the projects in a collaborative way, so each project is developed by several students from various Canadian universities, while they are advised by a supervisor from the academic or business world. As in the case of the Summer of Code and the Semester of Code, the projects solved by the students should be real problems posed by companies and projects related to Open Source.

The UCOSP project differs from others in four main areas:

1. The main objective, beyond development and solving real projects related to Open Source, is the development of students' professional skills and teamwork from a remote point of view. According to the organizers of this program, there are an increasingly number of jobs that require professionals trained to work in distributed and geographically dispersed development environments and able to be productive in them, communicating effectively with their workmates, using tools to coordinate work regardless of location or time zone, or even being able to work with people coming out of their usual circle of acquaintances or collaborators.

2. The project is oriented to students from a single country: Canada. It does not accept students from other countries of the world and is only intended to contribute to the education and training of the professional skills of students in this country.

3. Despite its features about working remotely and the distributed development, UCOSP programme collects as part of its workflow the initial work sessions in a face-to-face way. At them, the team members know each other personally in order to facilitate further work and allowing receiving training and guidance from those that will later be their mentors. Once this initial classroom training, students will return to their origin places to perform tele-work from there.

4. The rewards for developing projects are not monetary, but rely on credit recognition systems, achieving specific subjects or parts of their degrees, etc.

To develop this program, the UCOSP organizers use a web platform where projects are published (http://ucosp.ca/projects/). After selecting the projects that students want to develop, communication and management of the process are carried out of the platform, using techniques well known like messaging tools, code sharing repositories, email, etc. This programme has been operating since 2008, initially being an institutional project of several universities, and later becoming a stable project spread across Canada [20]. As a brief note about the popularity of this initiative, it can be highlighted that the UCOSP programme has received in the last four years more than 300 students from 20 different Canadian universities [21].

\section{DEMOLA}

According to its website [22], "Demola is an international organization that facilitates co-creation projects between university students and companies, either locally or internationally. To be more specific is [23]:

- A network that consists of various partners including universities, their faculties, researchers and students, as well as companies, local agencies and a growing number of Demola Centers around the globe. Not only are we international, we are interdisciplinary. 
- A process (...) that ensures that the work is systematic and runs on schedule. This way, the work itself can be as creative as possible, but the process keeps things under control both in terms of time and deliverable.

- A co-creation concept that is geared to solve real challenges. Every project has an outcome - be it a new concept, a demo, or a prototype. If the partner company finds the outcome useful, the company can license or purchase the outcome, and take it for further development.

- A framework that makes it easy for partners to come in and cooperate. Each partner has a clear role, and the work is guided by simple procedures. Contracts, intellectual property rights, licensing models, and other legal requirements are in place and meet international business standards and practices (sic)" [24].

Demola's mission as an organization is to create an innovation ecosystem worldwide. To do this, Demola puts in contact companies that offer real business problems both in terms of software as in other disciplines, with universities that offer direct access to talent and serve as a source of inspiration in the process of innovation, and students or researchers who eventually develop the solution and gain experience in a real professional context, following an approach in which everyone benefits (winwin approach) [25]. Demola's mission is not only focused on solving problems in a traditional way, but it uses the collaboration among the different stakeholders to give rise to new ideas and develop projects from an innovative and multidisciplinary perspective.

Regarding how this process is managed from a technological point of view, Demola establishes a network of associated centers, where each of them has its own website where the proposed projects, the activities to be performed, and the physical events are published for those interested in attending, etc. This system is based in most cases on a Drupal platform [26] that contains the functionality about roles, permissions, communication, publishing and content management, etc., enough for the implementation of the program in each of the venues. To illustrate this difference for each Demolacenter web platform, as example readers can visit the website of the Slovenian Demola center (http://slovenia.demola.net/).

About the relevance of the project, its viability and success in terms of attracting participants, Demola provides on its website some metrics about its activity. In [22] are available the year 2014 participation data, which comprise more than 9 Demola centers operating worldwide, more than 140 companies participating as partners in the project network, 1,600 students, 37 universities involved and 350 fulfilled projects.

\section{Semester of Code: Fundamentals ANd TeChNOlogical Solution}

As previously explained in the introductory section, the Semester of Code programme is an initiative arising from the VALS European project and proposes a framework for the organization and implementation of a virtual internship programme for students from European universities in a global professional context $[13-15,27,28]$.

This section explains in greater detail the foundations that support this programme, as well as the technological solution that supports it (as a whole) and its various processes and tasks.

A. Semester of Code's foundations

In this subsection is presented the Semester of Code's workflow, focusing the explanation on the key issues that have been developed, the different problems faced and solutions adopted during the first months of life of this virtual internship programme.

From a practical and pragmatic point of view, the Semester of Code is founded on two main pillars:

1. A process and workflow, called Open Innovation Process, that detail the practices system operation, and which has been designed to cover most of the possible needs that may arise to any stakeholder during the execution of their functions within the Semester of Code's process. This workflow describes the interaction between the different stakeholders involved, the relationship of these with the portal and the technology that supports the process and the process interaction with external stakeholders like the faculties staff, the administrative staff of universities, or the staff of companies or foundations, etc. The full description of this workflow and its actual implementation within institutions such as the University of Salamanca can be found in the references [13, 15, 28].

2. A number of components and technology platforms that provide both logic and practical to the entire process, facilitating the adoption of the Open Innovation Process to each participating institution and organization and articulating how the process should be developed effectively in actual application contexts. These components and platforms are described in detail in the next subsection, including a complete example of how they handle the entire process of managing virtual practices.

In addition to this brief explanation of the two main pillars of the Semester of Code, it is necessary to accompany an important clarification about the process and the system established for the management of the internship: the Semester of Code currently runs linearly in a way of sprints. That is, the Semester of Code's process is executed fully and in a linear fashion from start to finish; at this moment the Semester of Code is not a cycle that students can join at any time, but is regulated by a series of steps and associated timing constraints. It is not a continuously open system. Currently, for the pilot testing phase, two different sprints are being developed, one from September to December 2014 (in terms of stages of projects proposals, selection of students, etc., not for projects implementation phase) and another between January and March 2015 (the same way, regardless of the resolution 
phase of the proposals of the students). This is crucial to clearly understand how the software that supports the process is designed and implemented [29].

Another important fundamental of the Semester of Code is the rewards system and its win-win approach that is applied in all possible processes included [14]. This rewards system is made to ensure that all those involved in the process receive something (tangible or intangible) related to the process in an intrinsic way (i.e., in the case of companies: the possibility of student interns to solve a real business problem) or extrinsically (i.e., concrete rewards: the university agree with the students an academic reward which depends on the rules of the university and the educational legislation of the country where practices are developed). This policy about always rewarding somehow the effort made by those involved in the practices is what keeps the balance in the programme and makes their participation worthwhile.

As observed previously, and will be discussed in the fourth section (Results of the Semester of Code's First Iteration), if the reward policy is not set, there are several sensitive stakeholders that show doubts regarding their participation in the process (for example, the students).

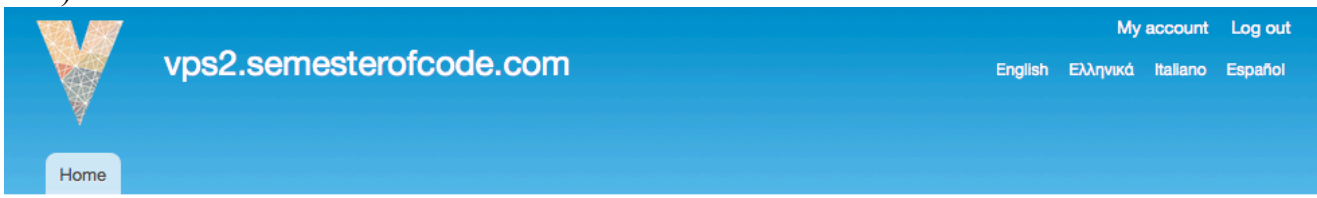

Home

\section{B. Technology serving the Semester of Code}

Supporting the Semester of Code there is a platform called Virtual Placements System (VPS) developed by the VALS project team, which is responsible for coordinating all processes and workflows defined by the Open Innovation Process for carrying out the placements program. This system is available currently via two web addresses: http://vps.semesterofcode.com/ and http://vps2.semesterofcode.com/ (one web address for each sprint carried out during the pilot testing).

This VPS platform is based on a series of plugins integrated in the Drupal CMS [26] which coordinate the various stages of execution and provide different features and capabilities to each stakeholder who can participate in the system. That is, these plugins control:

1. The timing of each type of event that may occur during the Semester of Code [29]: Project proposal periods, periods in which students can propose the ideas for solving projects, selection periods of proposals to be developed by the technological mentors, etc. For more information about the workflow and its timing: http://vps2.semesterofcode.com/sites/all/modules/vals soc/help/index.php?id=3

2. The actions each user can perform (i.e. Figure 1) [29]: registering different profiles, inviting mentors by companies, inviting academic supervisors and students by universities, proposing ideas for solving projects by students, etc.

3. The negotiation and agreement process on solving practical, management processes. These processes include the management of periods for project proposals and students election, the review process of the project ideas by the academic supervisors, the approval or rejection of solution ideas proposed by students (by the companies or foundations), the final acceptance of the placement done by the student, etc.

4. The necessary notifications associated with each process, i.e. warnings about registration procedures, new projects publication, solution proposals, processes of selecting students, decisions about practices, etc.

As discussed, the functionality varies depending on the type of user that interacts with the system. The different user profiles contemplated by the VPS are the following [29]: 
- Programme Administrator: user with administration and supervision permissions.

- Organization Manager: user that registers companies, foundations or projects. Has the possibility of sending projects to the system, performing the business mentor tasks, or inviting other mentors to oversee the implementation of projects.

- Mentor: can create projects in the system and controls the process of choosing candidates to develop the projects proposed by organizations.

- Institution administrator: user that registers the academic institution to which he/she belongs. Is authorized to be academic supervisor and invites other academic supervisors and students.

- Supervisor: can create students groups to manage the process of proposing solutions, invite students to participate and review the ideas proposed by students to business stakeholders.

- Student: can see listings of projects and participating companies, can choose the projects which he/she want to be proposed as a candidate to develop the solution and send their proposals to the system; they also have the final word in the candidates' selection process to finally accept or not the practice to be performed.

For more information on system operation and management of various processes occurring in the Semester of Code and the Open Innovation Process, please visit [29].

To ease the communication tasks, delivering different parts of the project, code-sharing, etc., the Semester of Code's process establishes that users involved in a project can choose the tools (external for example) they want to use for their work within the project.

\section{Results of THE SEMESTER OF CODE’s First ITERATION}

Upon the completion of the first iteration (first sprint) of the Semester of Code, which took place between September and December 2014, and which has already carried out the election of students and the acceptance and agreement on practices, it is possible to present some early results, as well as a series of observations, conclusions and future work to be done to improve the process and its results.

In terms of participation data, in the first round were involved (regarding organizations and institutions) 12 universities from 6 different countries (Spain, United Kingdom, Italy, Cyprus, Serbia, France), and 64 companies and foundations which provided 237 different projects. In relation to the students, in this first round the Semester of Code only received 12 proposals for the settlement of projects (only 12 students and several universities that failed to involve students). Of these students, seven of them achieved placements in companies or foundations, one of them was shortlisted as a potential solution (without actually materializing the choice), and 4 of them finally did not accept the placements, refusing the possibility of developing the proposed solution.

In light of these findings, the VALS project partners have attempted, through personal interviews with students, mentors, supervisors and academics, to identify the various problems that have occurred and to detect the strengths and weaknesses of the process. As a summary of this acquired knowledge, the following points are presented:

- Positive aspects observed about the project and its proposals:

o The universities like the VALS project proposal.

o The companies and foundations trust the process (at least 64 in the first round).

o Students believe that the practices performed within the Semester of Code programme are a great opportunity for their professional careers.

- Negative aspects observed about the projeet and its proposals:

o Universities need much time to react to these initiatives and adopt this kind of processes within their strict workflows and bureaucracy.

o Companies and foundations want to see results in the short term.

o Students need time to absorb this type of proposals and be motivated to participate in them.

- Issues found:

o Administrative processes at the universities are very strict, and vary between universities. The timing of these processes also changes depending on the university and the educational system of the country.

oThe deadlines and the workload of the companies or foundations are not always compatible with the plans of students.

o There are several critical factors in incorporating academic supervisors:

- Their personal relationships with organizers of the Semester of Code within their university.

- Their altruistic behavior, because in many universities the participation in initiatives such as this does not involve an extra revenue.

- They should see a clear link between practices and curriculum, so they can also get their work recognized.

o Students have various problems in getting involved:

- The Semester of Code must completely fit the timing of their degree or their short-term plans; otherwise, they will not participate.

- They must clearly know the advantages of the Semester of Code for them as well as the rewards they can receive. 
- They often believe that they do not have the knowledge to solve the projects proposed by companies.

- In some countries, students have reservations about the participation due to language (officially the Semester of Code is developed in English) or because they believe they do not have enough communication skills to function in a professional context like this (international, distributed, etc.).

In terms of concrete actions that the VALS project partners propose in order to alleviate these difficulties, the following can be highlighted:

- Make flexible the processes related to the incorporation of universities to the pilot. Each university will adapt the process to their own procedures as much as possible, especially in the most critical points that vary among them such as: recognizing and rewarding the placements, the time of completion of projects, etc.

- Perform another sprint within the scope of the Semester of Code's pilot tests, so the issues could be tested better in more European universities.

- Continuously monitor supervisors from universities, providing assistance in any aspect they need to carry out the Semester of Code within their institution.

- Present on several occasions and contexts the internships programme for students.

- Offer clearly and compulsorily attractive rewards for students, such as the recognition of credits or the possibility of reusing the projects developed within the Semester of Code scope as projects for subjects or Final Degree Projects.

- Involve more universities for a larger volume of potential students.

Among the future work proposed by the VALS project partners to improve the process and its results, it is possible to highlight the following ideas:

- Search for and involve academic supervisors previously involved in Open Source development and who have participated actively in FOSS communities.

- Assess the limitation of the number of projects received, so that in case of low participation by students, the ratio projectstudents would not be as much unbalanced.

- Interview students, supervisors and universities staff through questionnaires to learn more about the factors that influence their participation in the Semester of Code.

- Improve the features, user experience, documentation and appearance of the Virtual Placement System.

- Evaluate the option of having the enrollment process always open, in which the projects would have a predefined timing to be developed, and where students would participate at any time depending on their capabilities and personal schedule.

As a final summary of the first pilots experience within the Semester of Code, it is possible to assert that the human component in these initiatives is essential, and it is necessary that these programs find ways to connect with the proper target audience in every possible stakeholder that can be involved to achieve success.

This paper discusses the technological proposal of the VALS project and the Semester of Code programme to support the process of managing virtual placements in companies related to the Open Source development. Besides giving an explanation of the technology that supports this practices programme, this paper shows the preliminary results of the first phase of pilot tests of the programme, presenting the main problems, the negative and positive aspects found and some actions that should be taken by the project partners to improve the process and its results. In turn, this section about the preliminary results states that the human factor is a key point to the success of this kind of initiatives [30], because if the practices programme is unable to connect properly with the target audience to which it is addressed it will not succeed in any way.

To enable readers to establish a relationship between what this programme offers in the international context, this text highlights other different programmes that develop virtual practices worldwide, also explaining the main points of their philosophy and briefly their technological approach to the problem.

\section{ACKNOWLEDGEMENTS}

With the support of the Lifelong Learning Program of the European Union. Project Reference: 540054-LLP-1-2013-1- ESERASMUS-EKA. This project has been funded with support from the European Commission. This publication only reflects the views of the authors, and the Commission cannot be held responsible for any use that may be made of the information contained therein.

\section{REFERENCES}

C. van Dorp, "Stimulating European Employability through Cross Sector Virtual Mobility: European Funded Research on Flexible Modality Internships," By: Dorp, CA van, Virkus, S., Herrero de Egaña Espinosa de los Monteros. A., Baan, MK, Sepe, R., Stefanelli, C., Lansu, A., Lohr, A., Jasinska, M., and A. Wodecki. Publication co-funded by the Leonardo da Vinci programme (Lifelong Learning). European Association of Distance Teaching Universities (EADTU), Heerlen, the Netherlands, 2008.

[2] C. van Dorp, A. Lansu, M. Kocsis Baán, and S. Virkus, "Promoting the Learning Mobility of Future Workers: Experiments with Virtual Placements in University-Business Arrangements," eLearning Papers (http://www.elearningpapers.eu), December 2010. 
I. Op de Beeck, M. Vriens, and W. Van Petegem, "Enhancing International Work Placements Through Virtual Mobility: the EU-VIP project," in 18th EDINEB Conference 'From innovation to crème de la crème education, 2011, pp. 7-10.

[4] R. Kristensen, E. Källström, and J. Svenkerud, "Virtual Internships - Real Experience in a Virtual World. A best practice handbook for those interested in the concept of Internships in Business Education," European INTERN Project, 2002.

[5] M. Vriens, M. Achten, I. Op de Beeck, and W. Van Petegem, "Virtual mobility in international work placements," Learning and Sustainability. The New Ecosystem of Innovation and Knowledge. Book of Abstracts, pp. 62-62, 2011.

[6] M. Vriens, I. O. de Beeck, J. De Gruyter, and W. Van Petegem, "Virtual placements: improving the international work experience of students," EDULEARN10 Proceedings, pp. 1175-1183, 2010.

[7] F. J. García-Peñalvo, I. Álvarez Navia, J. R. García-Bermejo, M. Conde-González, A. García- Holgado, V. Zangrando, et al., "VALS: Virtual Alliances for Learning Society," in Proceedings of the TEEM'13 Track on Knowledge Society Related Projects, F. J. García-Peñalvo, A. GarcíaHolgado, and J. Cruz-Benito, Eds., ed Salamanca, Spain: Grupo GRIAL, 2013, pp. 19-26.

[8] Open Source Initative. (2012, 12/12/2014). The Open Source Definition. Available: http://opensource.org/docs/osd

[9] H. W. Chesbrough, Open innovation: The new imperative for creating and profiting from technology: Harvard Business Press, 2003.

[10] F. J. Garcia-Peñalvo, C. G. De Figuerola, and J. A. Merlo, "Open knowledge: challenges and facts," Online Information Review, vol. 34, pp. 520-539, 2010.

[11] F. J. García-Peñalvo, C. G. De Figuerola, and J. A. Merlo, "Open knowledge management in higher education," Online Information Review, vol. 34, pp. $517-519,2010$.

[12] M. S. Ramírez Montoya, "Acceso abierto y su repercusión en la Sociedad del Conocimiento: Reflexiones de casos prácticos en Latinoamérica," Education in the Knowledge Society (EKS), vol. 16, pp. 103-118, 2015.

[13] F. J. García-Peñalvo, J. Cruz-Benito, M. Á. Conde, and D. Griffiths, "Virtual placements for informatics students in open source business across Europe," in 2014 IEEE Frontiers in Education Conference Proceedings (October 22-25, 2014 Madrid, Spain), ed USA: IEEE, 2014 , pp. $2551-2555$.

[14] F. J. García-Peñalvo, J. Cruz-Benito, D. Griffiths, P. Sharples, S. Wilson, M. Johnson, et al., "Developing Win-Win Solutions for Virtual Placements in Informatics: The VALS Case," in Proceedings of the Second International Conference on Technological Ecosystems for Enhancing Multiculturality (TEEM'14), F. J. García-Peñalvo, Ed., ed New York, USA: ACM, 2014, pp. 733-738.

[15] F. J. García-Peñalvo, J. Cruz-Benito, M. Á. Conde González, and D. Griffiths, "Semester of Code: Piloting Virtual Placements for Informatics across Europe," in Proceedings of Global Engineering Education Conference, EDUCON 2015. Tallinn, Estonia, 18-20 Mach 20015, ed USA: IEEE, 2015, pp. 567-576.

[16] Google. (2014). Google Summer of Code (GSoC). Available: https://developers.google.com/open-source/soc

[17] Google. (2015, 1/1/2015). Google Summer of Code 2015, Frequent Asked Questions (FAQ). Available: http://www.googlemelange.com/gsoc/document/show/gsoc $\mathrm{program} /$ google/gsoc2015/help page

[18] Google. (2008). Google Melange. Available: https://code.google.com/p/soc/wiki/MelangeIntro

[19] Undergraduate Capstone Open Source Projects. (2014, 10/1/2015). About UCOSP. Available: http://ucosp.ca/about/

[20] R. Holmes, M. Craig, K. Reid, and E. Stroulia, "Lessons learned managing distributed software engineering courses," in Companion Proceedings of the 36th International Conference on Software Engineering, 2014, pp. 321-324.

[21] U. C. O. S. Projects. (2014, 10/1/2015). Historical Participation. Available: http://ucosp.ca/historical-participation/

[22] Demola. (2014, 12/12/2014). About Demola. Available: http://www.demola.net/about

[23] T. Kilamo, I. Hammouda, V. Kairamo, P. Räsänen, and J. P. Saarinen, "Applying Open Source Practices and Principles in Open Innovation: The Case of the Demola Platform," in Open Source Systems: Grounding Research, ed: Springer, 2011, pp. 307-311.

[24] T. Kilamo, I. Hammouda, V. Kairamo, P. Räsänen, and J.P. Saarinen, "Open Source, Open Innovation and Intellectual Property Rights-A Lightning Talk," in Open Source Systems: Long-Term Sustainability, ed: Springer, 2012, pp. 298-303.

[25] P. D. D. Einarson, "DEMOLA, THE UPCOMING WIN-WIN RELATIONSHIP BETWEEN UNIVERSITY AND INDUSTRY," in 10th International CDIO Conference, 2014.

[26] Drupal CMS. (2014). About Drupal. Ayailable: https://www.drupal.org/about

[27] Á. Fidalgo-Blanco, M. L. Sein-Echaluce Lacleta, D. Lerís, and F. J. García-Peñalvo, "Sistema de Gestión de Conocimiento para la aplicación de experiencias de innovación educativa en la formación," in Actas del II Congreso Internacional sobre Aprendizaje, Innovación y Competitividad, CINAIC 2013 Á. Fidalgo Blanco and M. L. Sein-Echaluce Lacleta, Eds., ed Madrid, Spain: Fundación General de la Universidad Politécnica de Madrid, 2013, pp. 750-755.

[28] F. J. García-Peñalvo, J. Cruz-Benito, B. Griffiths, and A. Achilleos, "Tecnología al servicio de un proceso de gestión de prácticas virtuales en empresas: Propuesta y primeros resultados del Semester of Code," VAEP RITA, vol. 3, pp. 52-59, 2015.

[29] VALS European Project. (2015, 10/1/2015). Semester of Code User Guide. Available: http://vps2.semesterofcode.com/sites/all/modules/vals soc/help/index.php

[30] F. J. García-Peñalvo, "Entrepreneurial and problem solving skills in software engineers," Journal of Information Technology Research, vol. 8, pp. ivvi, 2015.

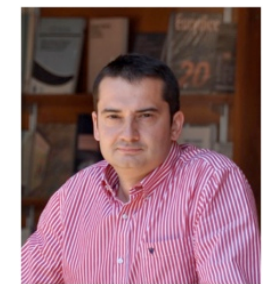

Francisco José García-Peñalvo completed his undergraduate studies in Computing at the University of Salamanca and University of Valladolid and his Ph.D. at the University of Salamanca. Dr. García-Peñalvo is the head of the research group GRIAL (Research Group Interaction and eLearning). His main research interests focus on eLearning, Computers \& Education, Adaptive Systems, Web Engineering, Semantic Web and Software Reuse. He has led and participated in over 50 research and innovation projects. He was Vice Chancellor for Innovation at the University of Salamanca between March 2007 and December 2009. He has published more than 300 articles in international journals and conferences. He has been guest editor of several special issues of international journals (Online Information Review, Computers in Human Behaviour, Interactive Learning Environments...). He is also a member of the program committee of several international conferences and reviewer for several international journals. At present, he is the Editor-in-Chief of the International Journal of Information Technology Research and the Education in the Knowledge Society Journal. Besides, he is the coordinator of the multidisciplinary PhD Programme on Education in the Knowledge Society.

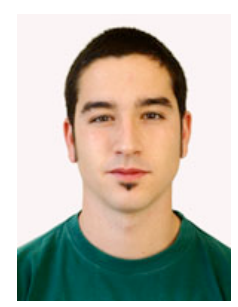

Juan Cruz Benito holds a Master Degree (MsC) in Intelligent Systems (2013, University of Salamanca, Spain) and is a PhD Candidate in Computer Sciences.

$\mathrm{He}$ is one of the youngest members of the GRIAL Research Group, where he specializes in software solutions based on technology ecosystems. He is an expert in Educational Virtual Worlds, Data Analytics and technologies for educational purposes, disciplines that he has developed in many innovation and research projects. He has participated in many European and national projects like TRAILER (Tagging, Recognition and Acknowledgment of Informal Learning Experiences), VALS (Virtual Alliances for Learning Society), USALSIM Virtual Campus, or the Spanish Observatory for University Employability and Employment (OEEU), where he participated as software engineer, researcher and developer. 


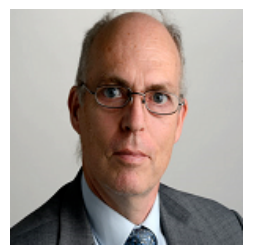

Dai Griffiths is Full Professor of the University of Bolton (United Kingdom). He has taught at many levels including primary and secondary education, higher education and continuing education, and as a consultant in industry. Since the early 1990s he has worked on a range of projects focusing on various aspects of technology and education, as a developer, researcher and project manager. In recent years a principal concern has been the development, use and implications of specifications for eLearning. In particular he has published extensively on IMS Learning Design, and the use of widgets in educational applications. He has worked on numerous European projects and is an experienced project coordinator.

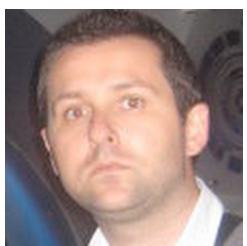

Achilleas Achilleos received his PhD from the School of Computer Science and Electronic Engineering at the University of Essex, cofunded by EPSRC and British Telecom (BT). Currently he is a post-doc researcher at SEIT, participating in the last few years in EU FP7, FP6, LLP and AAL projects: ongoing - PaaSage, Prosperity4All, VALS and completed - COIN, AsTeRICS, MUSIC and CVN, as well as EU proposals authoring. Research interests include context-awareness, smart technologies, mobile, service-oriented and cloud computing and model-driven development. He has published 30 papers in peer-reviewed journals, conferences, and book chapters. He has served as a TPC member and referee in repudiated journals and conferences.

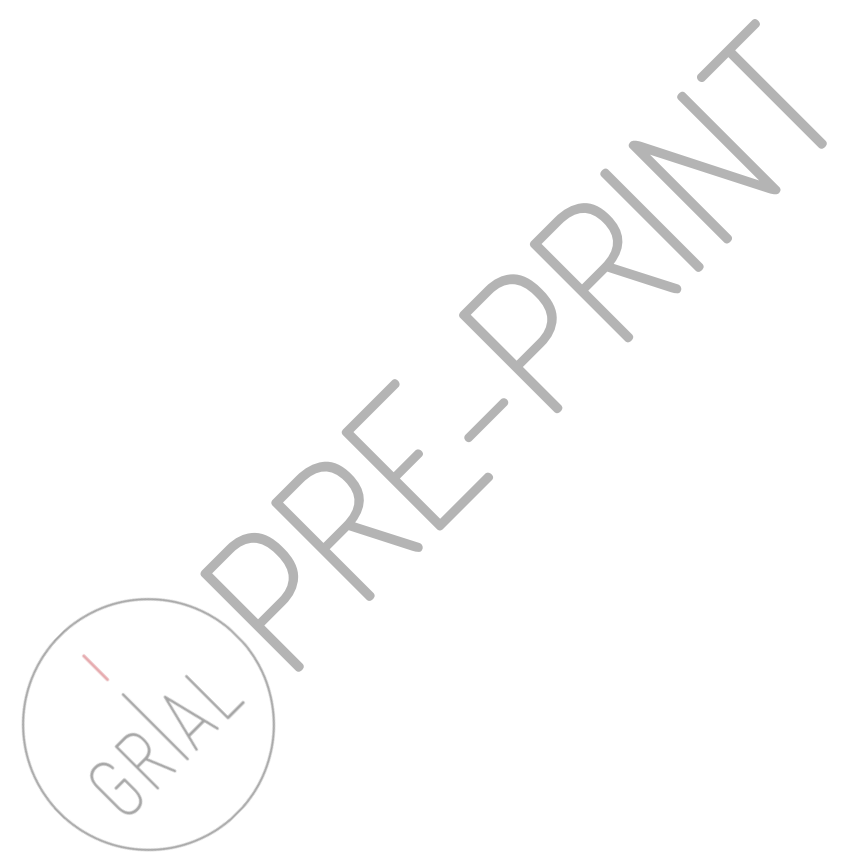

